\title{
Student Use of Qualitative Feedback while Taking Online Classes
}

\author{
Timothy Sawicki, Shawn O'Rourke \\ Canisius College, Buffalo, NY
}

\begin{abstract}
Online course enrollment continues to grow and it is imperative that studies consider researching all aspects of best practices for online teaching. One aspect that is critical to good online teaching practices is the aspect of providing online written qualitative feedback to the students. Past studies have looked at the importance of providing timely, high quality and specific feedback to online students. The current research extends aspects of student feedback by studying the extent to which online students are reading their online written feedback. Do students taking online courses read their written qualitative feedback? How often do they read it and when in a course do they most often read it is questions addressed in the current study. Findings revealed that students read their online feedback approximately $34 \%$ of the time. Students read major assignment feedback slightly more often they minor assignment feedback and they read feedback earlier in the course slightly more often than later in the course. A follow-up study showed that when students read online written feedback early in the course it lead to positive results. Recommendations for improving the reception of student written feedback are provided along with directions for future studies. Student-teacher year end evaluations are also discussed in relation to the current research and feedback.
\end{abstract}

\section{Introduction}

The proliferation of online courses and increased student enrollment in online education has created the necessity for research into best practices for online teaching. The latest data from 2011 showed there were 6.7 million students in higher education taking at least one online class and that represents $32 \%$ of all students in higher education registered in at least one online class (Online Learning Consortium, 2012)[7]. Almost 70\% of all school higher administrators feel online education is a part of their strategic plan for their university/college going forward. Providing students with written qualitative feedback on student assignments is an important aspect of online teaching and needed for a good online course. Assuring quality of online course delivery will be paramount for online teaching towards gaining the competitive edge in student enrollment [8]. One important component of a quality online course is well written qualitative feedback provided to the students. Student comments regarding the importance of feedback for learning have shown that quality feedback is necessary for good teaching and of utmost importance to the learning process (Nicol and Macfarlance-Dick) [6]. Other studies on feedback have focused on what good feedback should entail. Getzlaf, Perry, Toffner, Lamarche and Edwards [4] showed that the best student feedback is: positive, timely, future oriented, individualized, involves the learner and gently provides guidance towards improvement. Connexions [2] stated that meaningful feedback is necessary for a quality online course. The instructor should also provide recognition to students who have submitted good work and when necessary, feedback needs to be provided on specific ways to improve work. Mandernach and Garrett [5] discussed how, when and what should be included in the feedback presented to students. The 'when' includes timely feedback that is consistent, ongoing and is formative. The article goes on to state that the corrective feedback should be specific to the student and positive. The article concludes with the statement that the feedback creates a rapport of communication between the student and the instructor and feedback will have a direct effect on the overall course experiences the students have with a course. Studies such as Carless [1] showed on the other side that unclear feedback can occur based on the language the instructor uses and that can be detrimental to the learning process. Cavanaugh and Sawicki [3] showed that timely qualitative feedback from the instructor is one of the most important 'Likes' students have while taking online classes. Overall, student qualitative feedback is critical to a quality, well delivered online course and is part of good practices for online teaching. It would be a goal of every online instructor to have students read their online written qualitative feedback on every assignment. This should improve the students overall experience while taking online courses.

There are numerous studies on what constitutes good instructor feedback (i.e., best practices) both in the classroom and online teaching but there is little information on the extent to which students use instructor written qualitative feedback. This project came about as a result of anecdotal evidence related to student use of instructor feedback. Over the course 
of 12 years of teaching online and more than 100 online graduate classes at Canisius College taught by one instructor, it became apparent to that instructor that students appeared to making the same mistakes across course assignments. This phenomenon was peculiar because students were receiving in-depth written qualitative feedback on every assignment they submitted. In some cases the instructor on final exam and final projects would leave one full page of written qualitative feedback for the students. The instructor was recognizing that student mistakes were occurring after written feedback was given by the instructor to correct the errors that may occur in future submissions. For example, the online written feedback left for a student would state: "the use of an outside resource from a journal article or textbook to support your answer was missing." The instructor would then deduct a given number of points for that error. Non-improvement with the next submissions lead to questions in the instructors mind such as; are the students reading their written online feedback provided? Why are they making the same errors submission after submission if they are reading the feedback? To what extent are the students in the class reading the online instructor feedback? Specifically, are students reading online feedback provided for each assignment and do the students continue to read the feedback for the entire semester? In this study online written qualitative feedback was provided for every student on smaller module assignments and on major larger assignments by the instructor of the courses. The instructor has questioned over the years if students are reading any or all of the qualitative written feedback they are provided on the assignments. Whether students read their feedback while taking online courses is an important question to answer for online instructors and a question needed to be answered for best practices when teaching online.

\section{Method}

The current research reviewed the feedback patterns of five online classes taught by one instructor over a one year period. The study used two different graduate classes; PEG 651 Coaching Theory and Techniques (elective course) and PEG 660 Advanced Human Growth and Motor Development (compulsory course). The study was comprised of 68 Masters students taking either an elective or compulsory class in the online Masters Kinesiology program at Canisius College. Any student who took both of the classes during the study period was used only once for research purposes. It is noted that students were not directly informed by the instructor that written feedback was provided on each assignment in the courses they took. It was assumed by the instructor that students would check their grades and read their online written feedback on each assignment. The students took all courses through the Desire2Learn (D2L) online delivery system. D2L has a drop box which provides the notation 'Feedback Read' when a student has reviewed their written qualitative feedback. There is also a separate gradebook at the end of the course materials which provides only a letter/numerical grade for students to view. This research focused on whether the students checked their drop box to read their written qualitative feedback or whether they just went to the gradebook to read their letter/numerical grade or whether they reviewed both their online written feedback as well as their numerical/letter grade. The percentage of students reviewing their qualitative feedback was calculated along with the determination as to whether students reviewed their letter/numerical grade. Students reviewing their written qualitative feedback would also see their letter/numerical grade by default (since it is at the top of the written feedback). Students reviewing their letter/numerical grade would not see their written qualitative feedback by default (the gradebook only has letter/numerical grades available).

\section{Procedure}

Data was collected via the assignment drop box (called 'module' drop box for smaller assignments). Modules in this study refer to smaller weekly or biweekly assignments worth up to five points of a 100 point course total. Major assignments are worth up to 40 points on the 100 point course total and refer to final exams or final projects. The drop boxes provided online written qualitative feedback for each smaller module assignment along with feedback for major assignments. The drop box allows the instructor to determine if the students read their written qualitative feedback. One tally (one point) was recorded for each student who had the "Feedback Read" notation beside each drop box submission they made. The tallies allowed for percentage calculations of smaller module assignments and larger final project/final exam assignments for each student. Each course had ten smaller module assignments and one major assignment.

\section{Results and Discussion}

The results showed that in the five courses studied, a total of 748 written qualitative feedbacks were left by the instructor for the students to read on smaller module assignments and on major projects/exams. In reviewing the type of feedback; 680 occurrences of written qualitative feedback came from smaller module assignments and 68 occurrences of written feedback were provided on 
major projects/final exams. Percentages of student reviewing their written qualitative feedback were calculated based on smaller module and major assignments. Analysis determined: 1. if students looked at their feedback on each assignment, 2. if students looked at feedback more in the early part of the course than later in the semester 3. whether students looked at feedback on smaller assignments more than larger ones and 4. elective versus compulsory courses were also compared. Percentages were calculated to determine patterns of feedback reviewing by students across modules and major assignments and across different students.

Students reviewing their written qualitative feedback in totality for both minor module assignment and major assignments in all five courses were approximately $34 \%$ of the time $(254 / 748$ feedback read/feedback left). The results showed that regardless of assignment (module or major assignment), students are reviewing their online course assignments written qualitative feedback approximately $34 \%$ of the time. Table 1 demonstrates the tallies and percentage of student feedback (FB) read across all ten course modules and for final project/ the final exam.

Reviewing specific module assessment for the smaller assignments; students reviewed their written qualitative feedback left by instructor approximately $34 \%$ of the time $(228 / 680$ feedback read/feedback left). For major assignments worth up to 40 points of the course total, students reviewed their feedback $38 \%$ (26/68 feedback read/feedback left) of the time. The combined total percentage of students reading their online written qualitative feedback across all small module assignments and large final project/final exam assignments equaled close to $34 \%$. Other aspects analyzed in the study determined whether students looked at feedback more in the early parts of the course than later in the course. It was determined students reviewed their first course module in the five courses at a rate of approximately $43 \%$ (29/68). On the last module of the course (tenth module assignment), students reviewed their feedback at a rate of approximately 32\% (22/68). Combing total percentage of students reading their first three modules versus the last three modules of the course the percentage were: approximately $40 \%$ (for the first three modules) versus approximately $26 \%$ (for the last three modules). It is apparent that students read their written qualitative feedback early in the course at a more regular rate than later in the course. The first module assignment at almost $43 \%$ 'Feedback Read' was the highest read module of all ten modules in the course. It can be surmised that students receive and read their feedback on module one and feel that have a grasp of the requirements and then tend to check their feedbacks less of the time in subsequent modules. A third measure analyzed in the study was whether students reviewed larger assignments feedback more frequently than lesser valued assignments. It was determined students reviewed major assignments at a rate of approximately $38 \%$ (28/68 feedback read/feedback left) compared to approximately $34 \% \quad(228 / 680$ feedback read/feedback left) for smaller module assignments. This indicates students read major assignments written feedback slightly more often than smaller assignments. One of the classes of 18 students (course 4 in Table 1) was shown to have 'Feedback Read' on almost $67 \%$ of the final assignment reviewing drop box. This represents a striking improvement from other classes without any specific explanation to attribute it to. Other aspects analyzed in the study were whether elective classes differed from compulsory classes when analyzing student feedback reviewing patterns. Table 1 denoted ' $e$ ' for elective courses and ' $c$ ' courses for compulsory courses. The comparison showed no difference in elective versus compulsory course feedback reviewing by students. Feedback on elective classes occurred at a rate of approximately $34 \%$ while compulsory class reviewing of feedback occurred approximately $34 \%$ of the time.

Letter/numerical grades are available to the students by scrolling to the end of the course where the gradebook is located. The current research also analyzed whether students looked at the D2L grade book for their grades (letter or numerical grade only). It was shown that $100 \%$ of the students in all five courses logged into the grade book at least five times during the course and most viewed their grade book ten or more times during the course. In short, the students regularly checked their letter or numerical grade to determine how they did on smaller module and larger final project/final exam assignments. This suggests that students review their course numerical/letter grades at an extremely high frequency and this is the main source students use as feedback as to how they did on each assignment.

Another interesting data feature that came from the study was that students who began reading written feedback continue reading their feedback throughout the course. In all of the cases, students who reviewed all first three modules feedbacks stayed above an $80 \%$ review rate for the entire course. In other words, if I am a student who reads my written feedback and I do it early, I tend to continue reading my feedbacks for the entire course. The students who read their early feedback consistently ( $80 \%$ or above of the time) were shown to only miss an odd module for 'Feedback Read' as the course progressed. In contrast, students who missed reviewing their first three module feedbacks of the course remained at less than $20 \%$ feedback reviewing for the entire course. The students who regularly missed checking their early written feedback only found their way back to the module D2L drop box occasionally as the course progressed. 
Table 1. Table 1 Percentage of Feedback Read across Course Assignments

\begin{tabular}{|c|c|c|c|c|c|c|c|c|c|c|c|}
\hline $\begin{array}{l}\# \text { of } \\
\text { Students }\end{array}$ & Mod.1 & Mod.2 & Mod.3 & Mod.4 & Mod.5 & Mod.6 & Mod.7 & Mod. 8 & Mod.9 & Mod.10 & $\begin{array}{l}\text { Final } \\
\text { Exam/Proj. }\end{array}$ \\
\hline $\begin{array}{l}\text { Total/10e } \\
\text { Course } 1\end{array}$ & 5 & 4 & 3 & 4 & 5 & 3 & 2 & 2 & 2 & 5 & 1 \\
\hline $\begin{array}{l}\% \mathrm{FB} \\
\text { Read }\end{array}$ & 50 & 40 & 30 & 40 & 50 & 30 & 20 & 20 & 20 & 50 & 10 \\
\hline $\begin{array}{l}\text { Total } 13 \text { e } \\
\text { Course } 2\end{array}$ & 6 & 5 & 7 & 6 & 5 & 4 & 5 & 0 & 2 & 7 & 2 \\
\hline $\begin{array}{l}\% \text { FB } \\
\text { Read }\end{array}$ & 46.1 & 38.5 & 53.9 & 46.1 & 38.5 & 30.8 & 38.5 & 0 & 15.4 & 53.9 & 15.4 \\
\hline $\begin{array}{l}\text { Total } 17 \mathrm{c} \\
\text { Course } 3\end{array}$ & 8 & 8 & 7 & 6 & 6 & 7 & 4 & 4 & 3 & 2 & 9 \\
\hline $\begin{array}{l}\% \mathrm{FB} \\
\text { Read }\end{array}$ & 47.1 & 47.1 & 41.2 & 35.3 & 35.3 & 41.2 & 23.5 & 23.5 & 17.6 & 11.8 & 52.9 \\
\hline $\begin{array}{l}\text { Total } 18 \mathrm{e} \\
\text { Course } 4\end{array}$ & 6 & 7 & 5 & 4 & 6 & 9 & 5 & 7 & 5 & 5 & 12 \\
\hline $\begin{array}{l}\% \mathrm{FB} \\
\text { Read }\end{array}$ & 33.3 & 38.9 & 27.8 & 22.2 & 33.3 & 50 & 27.8 & 38.9 & 27.8 & 27.8 & 66.7 \\
\hline $\begin{array}{l}\text { Total/10c } \\
\text { Course } 5\end{array}$ & 4 & 3 & 3 & 3 & 3 & 5 & 3 & 3 & 2 & 3 & 2 \\
\hline $\begin{array}{l}\% \text { FB } \\
\text { Read }\end{array}$ & 40 & 30 & 20 & 30 & 30 & 50 & 30 & 30 & 20 & 30 & 20 \\
\hline Total $\%$ & 42.6 & 39.7 & 36.8 & 33.8 & 36.8 & 41.2 & 27.9 & 23.5 & 20.6 & 32.4 & 38.2 \\
\hline
\end{tabular}

*e or c beside number of students enrolled indicates elective course, c denotes compulsory course

This suggests that students who read their early written feedback found it helpful and continued reading it throughout the course while students who did not know about checking feedback or did not think about checking it, continued this pattern for the entire course. Encouraging early feedback reading would move online instructors towards the goal of having students read all of their online feedback left by the instructor.

\section{Conclusion}

The goal of every online instructor would be to have all students read all written qualitative feedback left on every assignment (100\% compliance rate). Instructors put a lot of effort into their online work and good instructors provide timely, specific, qualitative and personalized feedback to their students. This study hypothesized that students were not reading their online written feedback which was evident by students making the same mistakes on assignments continually when corrective feedback was available. The study confirmed that students were reading their written online qualitative feedback at low rates and this was likely the cause of students making the same errors on assignments over and over again. The results of the study showed that although students are regularly checking their numeric or letter grade, they are not checking their written qualitative feedback provided by the instructor as regularly (approximately 34\% of the time). The current study showed that getting students to review their feedback early in the course increases the likelihood they will review their feedback throughout the course. The results showed that once students read their written feedback early in the course they continue to read it at a high rate (above $80 \%$ 'Feedback Read'). This is an important finding in this study related to best practices for online teaching. The instructor of the course sending emails to students or information that written feedback is available may be a key to successfully having students read their written online feedback. In a quasi-experiment follow up to this study, the instructor posted announcements for the class that online written feedback is available to be read and the students should go to their the D2L drop box to read it. The announcement was posted at the start of the course and twice more during the semester. By posting announcements at the start of the course and in mid-semester the D2L web site automatically sends an email directly to the students alerting them to the announcement. The results of the quasiexperiment done after this study for the PEG 651 elective course for one class of 14 students showed a $78 \%$ 'Feedback Read' rate in module one. The quasiexperimental follow-up showed for module ten a $44 \%$ 'Feedback Read' rate. This showed an almost $50 \%$ increase in students reading their feedback from the original study used in this paper. It was shown in the quasi-experimental follow-up that if instructors regularly post reminders for students to read their online feedback more students will do it. If the goal 
of instructors is to have students read written qualitative online feedback $100 \%$ of the time, then it appears providing announcements and reminders for students to read it will enhance their feedback read rate. Further, it was shown in this study that if a student can be alerted to read their feedback and they do it, there is likelihood they will continue this trend for the entire course. This was evidenced by early feedback readers shown to read more than $80 \%$ of the instructor feedback and only miss the occasional module feedback provided. It is imperative for the instructor to make students aware and monitor if, students are reading the instructor feedback. Future studies which direct students to read their written feedback are critical to good online teaching. Perhaps asking the students for a reflection assignment which has the students use their written qualitative feedback would be a way to improve the number of students reading their written feedback.

\section{Future Research}

Replicating this study with more students, more courses, other instructors in this online program and replicating this study to other content fields would be a future endeavor. There was variance in the current study due to a small sample size so using more students in future studies would provide for a more rigorous test group. In light of this study, future studies should be directed at towards having a faculty member creates ways while teaching an online course to require the students to read their online written feedback. One possibility could have the students complete a reflection assignment which requires students to use the written feedback they had received on an assignment(s). A reflection assignment will require students to read their online written feedback and comment on it.

Another research question arising out of this study would be whether good students read their online written feedback more often than students who receive poor grades. It can be readily shown in D2L what final grade a student got and how often that student checked their online written feedback ('Feedback Read'). This could be a unique correlational study. It would be hypothesized that poorer students check both their online written feedback and gradebook less than good students.

An aspect not addressed in the current study but had some anecdotal data was that year end teacher evaluations were lower for the instructor in this study in the questions related to student feedback. In other words, students were scoring the teacher lower on year end teacher evaluations on the section and questions related to student feedback. Since only $34 \%$ of the students were reading their written feedback, it is logical that that year end teacher evaluations would be lower on questions related to giving students feedback. This is supported by work of Mandernach and Garrett [5] who stated that feedback creates important interpersonal connections between the student and the instructor. The use of feedback by the instructor will have an overall effect on the course experiences the students have with a course (which intuitively would affect year end teacher evaluations). Studying teacher evaluations related to feedback and determining if students were required to read their online feedback, whether that would improve year end teacher evaluations related to feedback should be studied.

\section{References}

[1] Careless, D. (2006). Differing Perceptions in the Feedback Process. Studies in Higher Education, 31(2), 219-233.

[2] Connexions. Best Practice in Online Teaching: Model Effective Online Interaction. See http://cnx.org/content/m15030/latest/

[3] Cavanaugh, L.K. and Sawicki, T.M. (2013). Students' Perceptions of Taking Online Physical Education Courses: A Qualitative Analysis. International Journal of Instructional Technology and Distance Learning, 10 (5), 65-71.

[4] Getzlaf, B., Perry, B., Toffner, G., Lamarche, K., and Edwards, M. (2007). Effective Instructor Feedback: Perceptions of Online Graduate Students. Journal of Educators Online, 6 (2), 1-22.

[5] Mandernach, J. and Garrett, J. (2014). Effective Feedback Strategies for the Online Classroom. Retrieved from http://www.facultyfocus.com/articles/onlineeducation/effective-feedback-strategies-online-classroom/ (July 2, 2016).

[6] Nicol, D. J., and Macfarlene-Dick, D. (2006). Formative assessment and self-regulated learning: a model and seven principles of good feedback practice. Studies in Higher Education, 31(2), 199-218.

[7] Online Learning Consortium (2012). Changing Course: Ten Years of Tracking Online Education in the United States. Retrieved from http://onlinelearningconsortium.org/ survey_report/changing-course-ten-years-tracking-onlineeducation-united-states/ (July 10, 2016).

[8] Ross, K. (2013). Evaluating the Wheel: Tips for Assuring Post-Design Quality of Online Courses. Retrieved from http://www.eduventures.com/2013/08/ evaluating-the-wheel-tips-for-assuring-post-design-qualityof-online-courses/ (July1, 2016). 